\title{
CHARACTERISTICS OF ADRENOCEPTORS IN THE HUMAN RADIAL ARTERY: CLINICAL IMPLICATIONS
}

Guo-Wei He, MD, PhD

Cheng-Qin Yang, MD
Objectives: The radial artery has been suggested to be spastic. Endogenous and exogenous catecholamines and the use of $\boldsymbol{\beta}$-blockers may be related to radial artery spasm, but the characteristics of adrenoceptors in this artery are unknown. This study was designed to characterize the $\alpha$ - and $\beta$-adrenoceptor in the human radial artery. Methods: Ring segments of the radial artery $(n=59)$ taken from patients undergoing coronary artery bypass grafting were studied in organ chambers. $\alpha$-Adrenoceptor agonists (norepinephrine, methoxamine, and UK14304) and antagonists (phentolamine hydrochloride [INN: phentolamine], prazosin, and yohimbine) were used to characterize the $\alpha$-adrenoceptor. $\beta$-Adrenoceptor function was studied in U46619-precontracted rings in response to isoproterenol (INN: isoprenaline). Results: Norepinephrine induced $6.9 \pm 0.6 \mathrm{gm}(80.6 \% \pm 6.8 \%$ of the contraction by $100 \mathrm{mmol} / \mathrm{L} \mathrm{KCl}$ ), and this was almost fully inhibited by phentolamine hydrochloride $(10 \mu \mathrm{mol} / \mathrm{L}, p<0.0001)$. The contraction force induced by methoxamine $(2.9 \pm 0.8 \mathrm{gm})$ was abolished by $0.5 \mu \mathrm{mol} / \mathrm{L}$ prazosin $(p=0.017)$. The contraction force induced by UK14304 (1.7 \pm 0.4 gm) was abolished by $1 \mu \mathrm{mol} / \mathrm{L}$ yohimbine. In contrast to the porcine coronary artery used as the control (fully relaxed to isoproterenol), radial artery rings did not have significant relaxation $(1.1 \% \pm 0.8 \%)$. Conclusions: The human radial artery is an $\alpha$-adrenoceptor-dominant artery with little $\boldsymbol{\beta}$-adrenoceptor function. The use of $\boldsymbol{\beta}$-blockers will not likely evoke the spasm of the radial artery. Furthermore, the radial artery has a dominant $\alpha_{1}$-adrenoceptor function, but the postjunctional $\alpha_{2}$-adrenoceptor is also functional. Circulating catecholamines will mainly contract the human radial artery by activation of the $\alpha_{1}$-adrenoceptors and to a lesser extent also by $\alpha_{2}$-adrenoceptors. (J Thorac Cardiovasc Surg 1998;115:1136-41) /arious autologous arteries have been used as grafts for coronary artery bypass grafting (CABG) with success. Those arteries are the inter-

From the Division of Cardiothoracic Surgery and Cardiovascular Research Laboratory, Grantham Hospital, Department of Surgery, University of Hong Kong, Hong Kong.

This study was supported by a Hong Kong Research Grants Council Grant (338/048/0001), the University of Hong Kong Committee of Research and Conference Grants (337/048/ 0018, 335/048/0079), and University of Hong Kong Grants (014/048/9602, 344/048/0001).

Received for publication July 1, 1997; revisions requested Oct. 16, 1997; revisions received Nov. 17, 1997; accepted for publication Dec. 9, 1997.

Address for reprints: Professor Guo-Wei He, MD, PhD, Chair of Cardiothoracic Surgery, University of Hong Kong, Grantham Hospital, 125 Wong Chuk Hang Rd., Aberdeen, Hong Kong. Copyright (c) 1998 by Mosby, Inc.

$0022-5223 / 98 \$ 5.00+0 \quad \mathbf{1 2 / 1 / 8 8 0 5 4}$ nal thoracic artery (ITA) and more recently arterial grafts such as the gastroepiploic artery and the inferior epigastric artery. Compared with these, the use of the radial artery has been more eventful. The radial artery was initially applied as a graft for CABG in 1971. ${ }^{1}$ However, it was soon abandoned because of the reported high incidence of vasospasm and low patency rates. ${ }^{2-4}$ With increased knowledge of spastic characteristics of this artery and of methods to overcome the spasm using pharmacologic agents, this arterial graft is again used. ${ }^{5}$ However, the long-term results of this graft are still pending.

According to the functional classification of arterial grafts, ${ }^{6}$ the radial artery belongs to type III, a type of graft that is more spastic than type I arteries (somatic arteries, such as the ITA and inferior epigastric artery). From our experience in agreement with others, ${ }^{7-11}$ the radial artery contraction 
(or spasm) is almost inevitably encountered during the operative dissection and warrants the use of vasodilators during harvesting, which is a key step in the revival of the use of the radial artery. ${ }^{5}$

The nature of the spastic characteristics of the radial artery is still unknown. Various vasoconstrictor substances have been suggested to be the spasmogens of human arterial grafts. ${ }^{12}$ Among those spasmogens, $\alpha$-adrenoceptor stimulants are important vasoconstrictors. Studies have demonstrated that the radial artery has a higher response to norepinephrine (NE), 5-hydroxytryptamine, ${ }^{7}$ angiotensin II, and endothelin- $1^{11}$ than the ITA. It is obviously important to identify the characteristics of the adrenoceptors in the radial artery. First, the responses of the human radial artery to catecholamines are clinically important during and after operation. The stimulation by catecholamines of $\alpha$-adrenoceptors may be the cause of the radial artery spasm. As to the response to catecholamines, knowledge of the subtypes of $\alpha$-adrenoceptors in the human radial artery is important because the effects of circulating catecholamines (endogenous or exogenous) on this artery might therefore be predicted. During the perioperative period in patients in critical condition receiving intravenous catecholamines, this is particularly important; also, many patients who undergo CABG are taking $\beta$-blockers. Whether the use of the $\beta$-blockers will evoke radial artery spasm perioperatively depends largely on the function of the $\beta$-adrenoceptor in this artery and this is unknown.

In view of these clinical implications this work was designed to investigate the subtypes of $\alpha$-adrenoceptors and the function of $\beta$-adrenoceptors in the human radial artery by receptor agonists and antagonists.

\section{Methods}

General. Human radial artery segments were collected from patients undergoing $\mathrm{CABG}$ with these grafts. Approval to use discarded radial artery tissue was given by the Human Ethics Committee of the Grantham Hospital. After the radial artery was dissected, the required length was carefully measured. Any discarded segments of radial artery were immediately collected and placed into a container with oxygenated physiologic (Krebs) solution maintained at $4^{\circ} \mathrm{C}$ and then transferred to the laboratory. The vessels were placed in a glass dish and dissected out from their surrounding connective tissue. The arteries were cut into $3 \mathrm{~mm}$ long rings and then suspended on wires in organ baths. ${ }^{13}$ The number of rings provided by each patient varied from 2 to 4 . The Krebs solution had

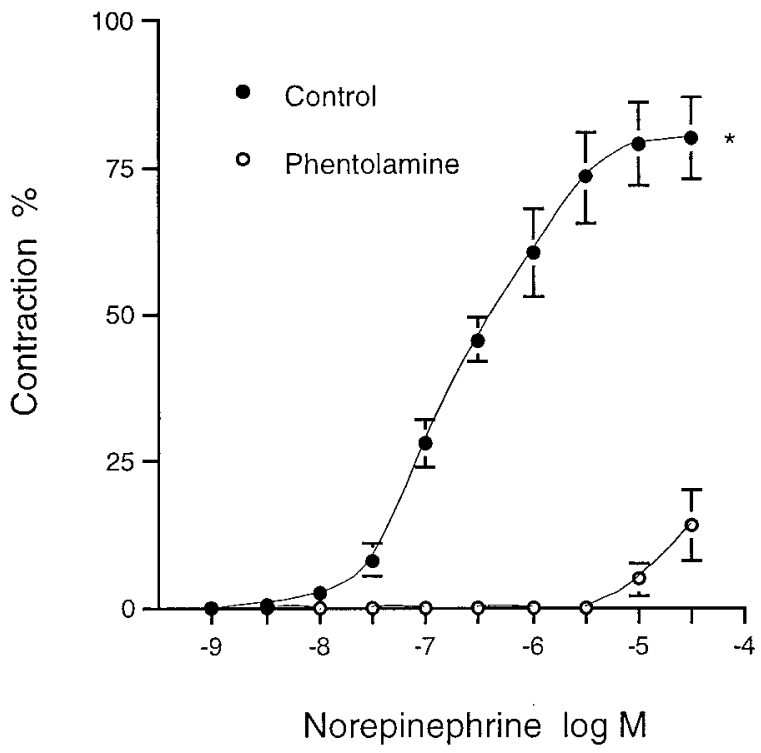

Fig. 1. Mean concentration (-log mol/L)-contraction (percentage of $100 \mathrm{mmol} / \mathrm{L} \mathrm{K}^{+}$-induced contraction) curves for $\mathrm{NE}$ in the human radial artery. Two rings obtained from each patient were allocated to each treatment. One ring was the control (O) without pretreatment of phentolamine. For the other ring phentolamine, $10 \mu \mathrm{mol} / \mathrm{L}$ (O), was added into the organ bath 30 minutes before the start of the NE curve. Symbols represent data averaged from six rings (from six patients). Vertical error bars are 1 standard error of mean values. ${ }^{*} p<0.0001$.

the following composition (in millimoles per liter): $\mathrm{Na}^{+}$, $144 ; \mathrm{K}^{+}, 5.9 ; \mathrm{Ca}^{2+}, 2.5 ; \mathrm{Mg}^{2+}, 1.2 ; \mathrm{Cl}^{-}, 128.7 ; \mathrm{HCO}_{3}^{-}, 25$; $\mathrm{SO}_{4}{ }^{2-}, 1.2 ; \mathrm{H}_{2} \mathrm{PO}_{4}^{-}, 1.2$; and glucose, 11 . The solution was aerated with a gas mixture of $95 \%$ oxygen to $5 \%$ carbon dioxide at $37^{\circ} \pm 0.1^{\circ} \mathrm{C}$.

Organ-bath technique. A specially designed organbath technique was used for this study. This technique allows for the vascular rings to be subject to normal physiologic pressure in vitro comparable to that in vivo. The details of the technique were previously published. ${ }^{14,15}$ In brief, each arterial ring was stretched in progressive steps to determine the individual lengthtension curve. A computer iterative fitting program (VESTAND 2.1, Yang-Hui He, Princeton University, N.J.) was used to determine the exponential line, pressure, and internal diameter. When the transmural pressure on the rings reached $100 \mathrm{~mm} \mathrm{Hg}$, determined from their own length-tension curves, the stretch procedure was stopped and the rings were released to return to $90 \%$ of their internal circumference at $100 \mathrm{~mm} \mathrm{Hg}$. This degree of the passive tension was then maintained throughout the experiment.

Because of the importance of endothelium on vascular tone, we intentionally preserved the endothelium by cautiously dissecting and mounting the rings. We previously found that this technique allowed the experiments to be 


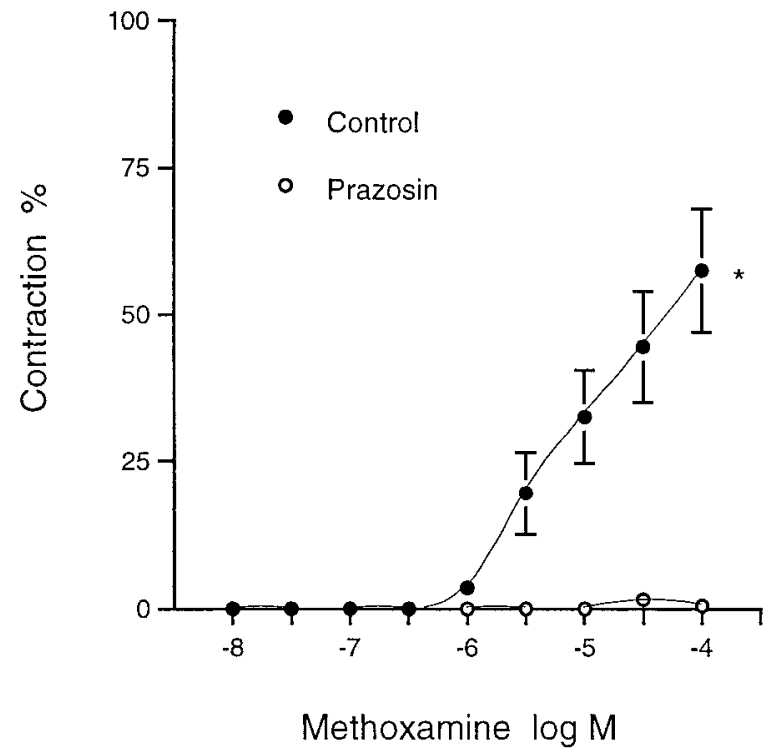

Fig. 2. Mean concentration (-log mol/L)-contraction (percentage of $100 \mathrm{mmol} / \mathrm{L} \mathrm{K}^{+}$-induced contraction) curves for $\mathrm{MO}$ in the human radial artery. Two rings obtained from each patient were allocated to each treatment. One ring was the control (O) without pretreatment of phentolamine. For the other ring prazosin, $0.5 \mu \mathrm{mol} / \mathrm{L}$, (O) was added into the organ bath 30 minutes before the start of the NE curve. Symbols represent data averaged from six rings (from six patients). Vertical error bars are 1 standard error of mean values. ${ }^{*} p<0.001$.

carried out with an intact endothelium, as determined by the functional relaxation response to endothelium-derived relaxing factor agonists in the human radial artery ${ }^{11}$ and porcine coronary artery. ${ }^{16}$ To examine the role of endothelium in our study, the endothelium in four rings was removed mechanically by using a fine wood stick moistened with Krebs solution to gently rub the intima of the rings. ${ }^{14,16}$ The response to an endothelium-derived relaxing factor stimulus, calcium ionophore A23187, in U46619-precontracted radial artery rings was compared in the endothelium-intact and the endothelium-denuded rings.

Protocol. After the normalization procedure, the radial artery rings were equilibrated for 60 minutes. $\mathrm{KCl}(100$ $\mathrm{mmol} / \mathrm{L}$ ) was added to test the viability of the vessel, and the contraction force was used as the control. Vessels were discarded if they did not respond to $\mathrm{KCl}$. The radial artery ring was then washed and subject to the following protocols. The radial artery rings were randomly distributed to different groups, disregarding preoperative drug therapy. However, in $\beta$-adrenoceptor functional studies pilot experiments showed that this function is weak in the radial artery; therefore, for this part of the study, radial artery rings were taken from four patients (in three patients no $\beta$-adrenoceptor blockers were given preoperatively to exclude any possible effect of the drug).

\section{$\alpha$-Adrenoceptor agonists and antagonists}

$\alpha_{1}$ - and $\alpha_{2}$-Adrenoceptor agonist $N E$ and $\alpha_{1^{-}}, \alpha_{2}$-antagonist phentolamine. Two rings from a patient were allocated in two groups (six rings for each group). One ring was set as a control for NE concentration-contraction curve while the other ring was incubated in $-5 \log \mathrm{mol} / \mathrm{L}$ phentolamine hydrochloride (INN: phentolamine) (an $\alpha_{1}$ - and $\alpha_{2}$-adrenoceptor antagonist) for 30 minutes before the NE concentration-contraction curve was constructed.

$\alpha_{1}$-Agonist methoxamine and $\alpha_{1}$-antagonist prazosin. Two radial artery rings obtained from a patient were allocated into two groups (six rings for each group). One ring was used as a control, and a concentration-contraction curve to methoxamine (MO) was constructed from this ring. The second ring was incubated in $-6.3 \log \mathrm{mol} / \mathrm{L}$ $(0.5 \mu \mathrm{mol} / \mathrm{L})$ prazosin (an $\alpha_{1}$-adrenoceptor antagonist) for 30 minutes before a concentration-contraction curve to $\mathrm{MO}$ was constructed.

$\alpha_{2}$-Agonist UK14304. A highly selective $\alpha_{2}$-adrenoceptor agonist UK14304 was given to test the $\alpha_{2}$-adrenoceptors in the radial artery $(n=11)$. Concentration-contraction curves to UK14304 ( -9 to $-5 \log \mathrm{mol} / \mathrm{L})$ were constructed. Rings $(n=9)$ were then washed and incubated in $-6 \log \mathrm{mol} / \mathrm{L}$ yohimbine (a selective $\alpha_{2}$-adrenoceptor antagonist) for 30 minutes before the second concentration-contraction curves were constructed.

$\boldsymbol{\beta}$-Adrenoceptor agonists and antagonists. Ten radial artery rings were contracted by U46619 (10 nmol/L). When the contraction reached a stable plateau, cumulative concentration-response curves for isoproterenol (INN: isoprenaline) were obtained by adding this agent to the organ chamber. After the isoproterenol curve was completed, nitroglycerin $(30 \mu \mathrm{mol} / \mathrm{L})$ was added to determine whether the rings were still capable of further relaxation. Because the relaxation induced by isoproterenol was minimum in the radial artery rings, the porcine coronary artery, a vessel known to possess a strong $\beta$-adrenoceptor function, was studied in terms of its response to isoproterenol as the control $(n=6)$.

In all experiments except those with UK14304 each radial artery ring was used for only one concentrationcontraction curve.

Data analysis. The effective concentration of the contraction or relaxation agent that caused $50 \%$ of maximal contraction (or relaxation) was defined as $\mathrm{ED}_{50}$. The $\mathrm{EC}_{50}$ was determined from each concentration-relaxation curve by a logistic, curve-fitting equation: $\mathrm{E}=\mathrm{MA}^{\mathrm{P}} /\left(\mathrm{A}^{\mathrm{P}}+\mathrm{K}^{\mathrm{P}}\right)$, where $E$ is response, $M$ is maximal contraction (or relaxation), $A$ is concentration, $K$ is $\mathrm{EC}_{50}$ concentration, and $p$ is the slope parameter. ${ }^{14,15}$ From this fitted equation, the mean $\mathrm{EC}_{50}$ value \pm standard error of the mean was calculated for each group.

Maximal responses in two groups of rings were compared by unpaired $t$ test. Results are expressed as mean ( \pm standard error).

Drugs. Drugs used in this study and their sources were: (-) NE bitartrate, MO, phentolamine (Sigma Chemical Company, St. Louis, Mo.); yohimbine (Tokyo, Kasei, Japan); UK14304 and prazosin (Pfizer, New York, N.Y.); stock solutions were kept in the refrigerator. 


\section{Results}

Fifty-nine human radial artery ring segments were used in this study. The diameter of the rings at a transmural pressure of $100 \mathrm{~mm} \mathrm{Hg}$ was $2.3 \pm 0.2$ $\mathrm{mm}$ (standard error). The transmural pressure on the vascular wall during the experiments determined by their own length-tension curves was $71.9 \pm 5.2$ $\mathrm{mm} \mathrm{Hg}$. The resting force on the vascular wall was $2.2 \pm 0.19 \mathrm{gm}$.

Functional test on endothelium. In the endothelium-preserved rings A23187 caused 62.9\% $\pm 6.0 \%$ of relaxation of U46619-induced contraction, whereas in the endothelium-denuded rings A23187 caused no relaxation at all.

$\alpha_{1}$ - and $\alpha_{2}$-agonist $\mathrm{NE}$ and antagonists. NE induced $6.9 \pm 0.6 \mathrm{gm}(80.6 \% \pm 6.8 \%$ of the contraction by $100 \mathrm{mmol} / \mathrm{L} \mathrm{KCl})$, and $\alpha_{1}$ - and $\alpha_{2}$-antagonist phentolamine $(10 \mu \mathrm{mol} / \mathrm{L})$ almost fully inhibited this contraction $(0.9 \pm 0.4 \mathrm{gm}, p<0.0001$, Fig. 1$)$. Compared with the $\mathrm{EC}_{50}$ of $-6.63 \pm 0.12 \log \mathrm{mol} / \mathrm{L}$ in the control rings, in those treated with phentolamine, because of the total abolishment of the contraction, the $\mathrm{EC}_{50}$ could not be calculated with the above equation.

$\alpha_{\mathbf{1}}$-Agonists and antagonists. The maximum contraction force induced by MO was $2.9 \pm 0.8 \mathrm{gm}$ $(57.1 \% \pm 10.5 \%$ of the contraction by $100 \mathrm{mmol} / \mathrm{L}$ $\mathrm{KCl})$, and it was abolished $(0.2 \pm 0.2 \mathrm{gm})$ by 0.5 $\mu \mathrm{mol} / \mathrm{L}$ prazosin $(p=0.017$, Fig. 2$)$. Similar to the results in the NE experiments, compared with the $\mathrm{EC}_{50}$ of $-4.77 \pm 0.33 \log \mathrm{mol} / \mathrm{L}$ in the control rings, in those treated with phentolamine, because of the total abolishment of the contraction, the $\mathrm{EC}_{50}$ could not be calculated with the above equation.

$\boldsymbol{\alpha}_{2}$-Agonist UK14304. The maximum contraction force induced by UK14304 was $1.7 \pm 0.4 \mathrm{gm}(28.3 \%$ $\pm 6.4 \%$ of the contraction by $100 \mathrm{mmol} / \mathrm{L} \mathrm{KCl}$ ), and it was abolished $(0.1 \pm 0.1 \mathrm{gm})$ by $1 \mu \mathrm{mol} / \mathrm{L}$ yohimbine (Fig. 3). In one ring UK14304 did not evoke contraction. The $\mathrm{EC}_{50}$ for the rest of the rings $(n=10)$ was $-6.13 \pm 0.2 \log \mathrm{mol} / \mathrm{L}$.

$\boldsymbol{\beta}$-Adrenoceptor agonists and antagonists. In the radial artery rings contracted by U46619 isoproterenol did not induce any significant relaxation $(1.1 \%$ $\pm 0.8 \%$, Fig. 4$)$, although the vessels were fully relaxed with nitroglycerin $(30 \mu \mathrm{mol} / \mathrm{L})$ at the end of the experiment. In contrast, the porcine coronary artery was fully relaxed with isoproterenol $(97.6 \% \pm$ $1.2 \%$, Fig. 4).

\section{Discussion}

This study, for the first time, demonstrates that (1) the human radial artery is an $\alpha_{1}$-adrenoceptor-

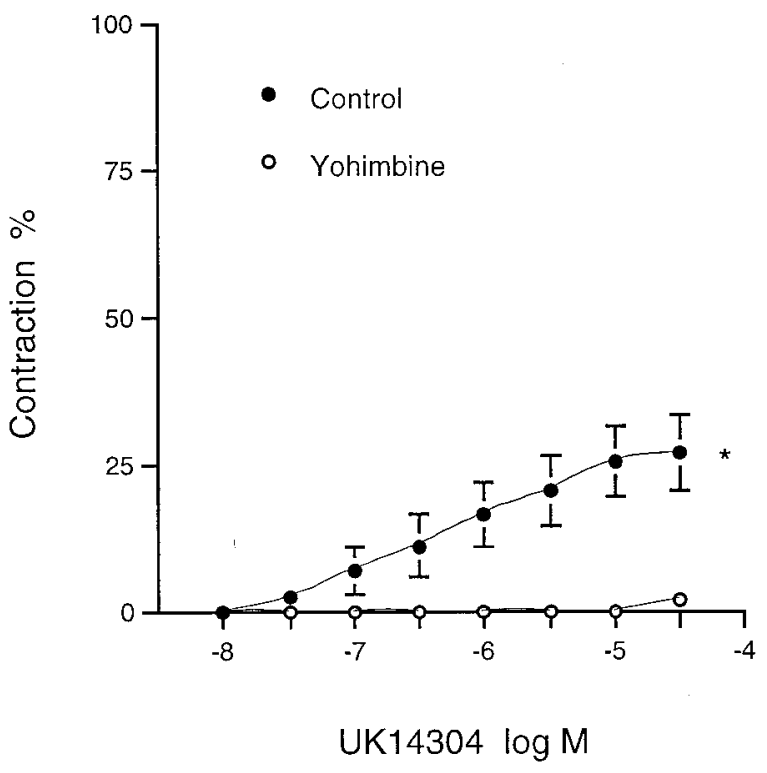

Fig. 3. Mean concentration (-log mol/L)-contraction (percentage of $100 \mathrm{mmol} / \mathrm{L} \mathrm{K}^{+}$-induced contraction) curves for UK14304 in the human radial artery. Cumulative concentration-contraction curves were established for UK14304 (,$n=11)$. The rings were then repeatedly washed to reestablish the baseline. Yohimbine $(1 \mu \mathrm{mol} / \mathrm{L})$ was added 30 minutes before the second concentrationcontraction curves to UK14304 were established $(\bigcirc, n=$ $9)$. Vertical error bars are 1 standard error of mean values. ${ }^{*} p<0.01$.

dominant artery with little $\beta$-adrenoceptor function and (2) the post- $\alpha_{1}$-adrenoceptor is dominant although $\alpha_{2}$-function also exists. Therefore circulating catecholamines will primarily contract the radial artery through the $\alpha_{1}$-mechanism and the use of $\beta$-blockers will unlikely evoke radial artery contraction or spasm during and after CABG.

Operative results (early mortality and long-term patency) of CABG depend at large on the function of the graft. For the radial artery the major concern is its spastic characteristic with subsequent occlusion leading to the initial abandonment of this arterial graft. The spastic characteristic of the radial artery has been demonstrated experimentally. ${ }^{71}$ The radial artery is more reactive to NE, 5-hydroxytryptamine, ${ }^{7}$ angiotensin II, and endothelin- ${ }^{11}$ than is the ITA.

Adrenoceptors are composed of $\alpha$ - and $\beta$-subtypes. In large arteries $\alpha$-adrenoceptors mediate contraction, whereas $\beta$-adrenoceptors, relaxation. If the function of the $\beta$-adrenoceptor is strong, the artery tends to contract when $\beta$-blockers are given 


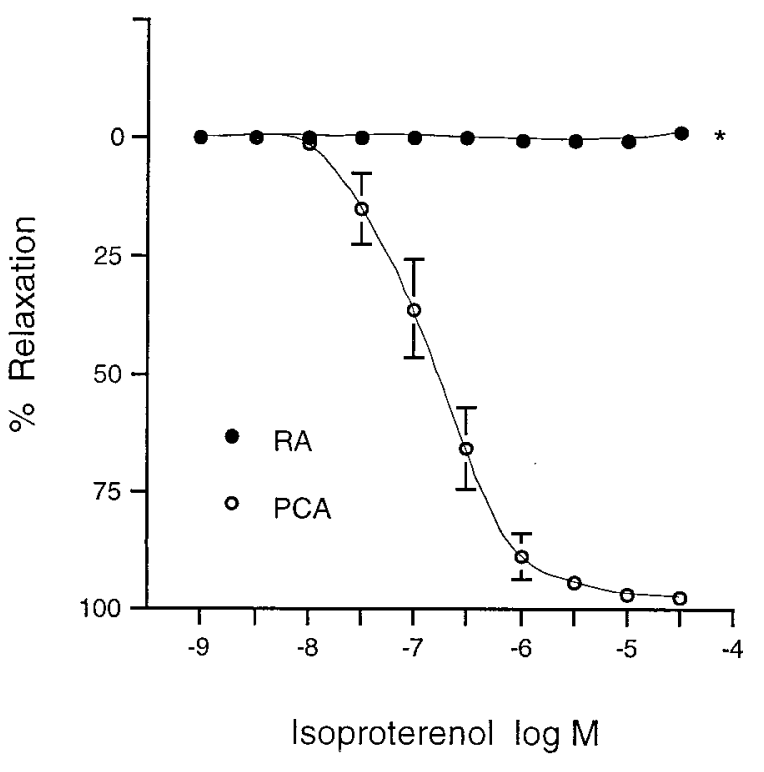

Fig. 4. Mean concentration (-log $\mathrm{mol} / \mathrm{L})$-response (\% relaxation) curves for isoproterenol in the human radial artery $(R A)$ precontracted by U46619 (10 nmol/L) $(\mathbf{O}$, $p=10$, taken from four patients). All the artery segments were fully relaxed to nitroglycerin $(30 \mu \mathrm{mol} / \mathrm{L})$ at the end of the experiment. Porcine coronary arteries $(P C A)$ were used as the control $(\bigcirc, n=6)$. Vertical error bars are 1 standard error of mean values. ${ }^{*} p<0.0001$.

because the $\beta$-adrenoceptor-mediated relaxation is eliminated as reported in coronary arteries. ${ }^{17}$ One of the aims of this study is to investigate whether this mechanism is involved in the radial artery spasm. Our study results clearly demonstrate that this is not the case because the human radial artery has little $\beta$-adrenoceptor-mediated function. This is shown in the result that isoproterenol, a full $\beta$-agonist, did not induce significant relaxation. In these experiments the radial artery was taken from four patients while three of them were not taking $\beta$-blockers. This ruled out the possibility that the minimal $\beta$-mediated relaxation was due to the preoperative use of $\beta$-blockers. The full relaxation induced by isoproterenol in the porcine coronary artery suggests that our method is suitable to study the $\beta$-function and reveals a tremendous difference in $\beta$-function between these two arteries. We previously studied the $\beta$-adrenoceptor function in the human ITA $^{15}$ and showed weak relaxation of the artery. In this study we have demonstrated that the $\beta$-adrenoceptor function is even weaker in the radial artery than in the ITA.

Postjunctional $\alpha$-adrenoceptors are composed of $\alpha_{1}$ - and $\alpha_{2}$-subtypes. It is generally recognized that in vascular smooth muscle postjunctional $\alpha_{1}$-adrenoceptor is the predominant vasoconstrictor type, although stimulation of postjunctional $\alpha_{2}$-adrenoceptors can also induce vasoconstriction. ${ }^{18-20}$ The contribution of $\alpha_{2}$-adrenoceptors to drug-induced vasoconstriction depends on particular vessels and species, as well as the diameter of the blood vessels. ${ }^{21-22}$ It has been suggested that $\alpha_{1}$-adrenoceptors are predominantly norepinephrinergic in nature and are located extrajunctionally and prejunctionally. ${ }^{23-25}$ Medgett and Langer ${ }^{26}$ reported that vasoconstrictor responses to exogenous agonists are mainly mediated by the $\alpha_{2}$ adrenoceptors in the cat middle cerebral artery, but the $\alpha_{2}$-adrenoceptors do not mediate neuronal sympathetic vasoconstrictions because they are mainly located extrajunctionally. However, more recently, it has been shown that postsynaptic $\alpha_{2}$-adrenoceptors can be involved in the vasoconstrictor response to sympathetic nerve stimulation to a significant ${ }^{20}$ or even predominant degree. ${ }^{18}$ In this article we use the term postjunctional $\alpha_{2}$-adrenoceptor to differ from the presynaptic $\alpha_{2}$-adrenoceptor. In this study we found that $\mathrm{NE}$ (an $\alpha_{1^{-}}$and $\alpha_{2}$-agonist) produced a significantly greater maximum contraction force than MO (an $\alpha_{1}$-agonist) did (6.9 \pm 0.6 vs $2.9 \pm$ $0.8 \mathrm{gm}, p<0.01$ ), and this suggests that postjunctional $\alpha_{2}$-adrenoceptors may play a role in the NE-induced contraction in the human radial artery. This is further supported by the UK14304-induced contraction. UK14304 is a pure $\alpha_{2}$-agonist, ${ }^{27}$ and it produced contractions in 10 of 11 radial artery rings in our experiments. The contraction could be totally inhibited by yohimbine, an $\alpha_{2}$-antagonist. These experiments suggest that the postjunctional $\alpha_{2}$-adrenoceptor is functional in the human radial artery. Compared with the previous finding in the human ITA showing the ITA to have little $\alpha_{2}$-adrenoceptor function, the radial artery probably had slightly higher $\alpha_{2}$-adrenoceptor-mediated function.

Although both postjunctional $\alpha_{1}$ - and $\alpha_{2}$-adrenoceptors mediate contraction, the identification of the subtypes of the adrenoceptors has some clinical implications in predicting the role of circulating catecholamines, which are frequently administered perioperatively for $\mathrm{CABG}$. In our study the response to the pure $\alpha_{1}$-agonist $\mathrm{MO}$ has demonstrated the functional role of this subtype of the adrenoceptor. In contrast UK14304 evoked significantly less contraction $(57.1 \% \pm 10.5 \%$ vs $28.3 \% \pm 6 \%, p<$ $0.05)$. This shows the predominance of the $\alpha_{1}$ adrenoceptor in the human radial artery. Therefore this study demonstrates that the human radial ar- 
tery, like the human ITA, is $\alpha_{1}$-predominant and has weak $\beta$-mediated relaxation. However, unlike the human ITA in which there is little evidence of the existence of postjunctional $\alpha_{2}$-adrenoceptors, the human radial artery evidently has such $\alpha_{2}$-function.

In conclusion, our study demonstrates that the human radial artery is an $\alpha$-adrenoceptor-dominant artery with little $\beta$-adrenoceptor function. The use of $\beta$-blockers will not likely evoke spasm of the radial artery. With regard to the subtypes of the $\alpha$-adrenoceptors, the radial artery has a dominant $\alpha_{1}$-function, but the postjunctional $\alpha_{2}$-adrenoceptor is also functional. Circulating catecholamines will mainly contract the human radial artery, and the contraction is mediated by activation of the $\alpha_{1}$-adrenoceptors and, to a lesser extent, the $\alpha_{2}$-adrenoceptors. Therefore such contraction may be effectively antagonized by $\alpha_{1}$ - and $\alpha_{2}$-adrenoceptor antagonists.

We gratefully acknowledge the cooperation of the cardiologists, the technical assistance of the surgical medical officers at the Division of Cardiothoracic Surgery, and the operating theater nurses and technicians at Grantham Hospital, Hong Kong.

\section{REFERENCES}

1. Carpentier A, Guermonprez JZ, Deloche A, Frechette C, Dubost $\mathrm{C}$. The aorto-to-coronary radial artery bypass graft: a technique avoiding pathological changes in grafts. Ann Thorac Surg 1973;16:111-21.

2. Fisk RL, Bruoks CH, Callaghan JC, Dvorkin J. Experience with the radial artery graft for coronary bypass. Ann Thorac Surg 1976;21:513-8.

3. Carpentier A. Discussion of Geha AS, Krone RJ, McCormick JR, Baue AE. Selection of coronary bypass: anatomic, physiological, and angiographic considerations of vein and mammary artery grafts. J Thorac Cardiovasc Surg 1975;70:414-31.

4. Chiu C-j. Why do radial artery grafts for aortocoronary bypass fail? A reappraisal. Ann Thorac Surg 1976;22:520-3.

5. Acar C, Jebara VA, Portoghese M, Beyssen B, Pagny JY, Grare $\mathrm{P}$, et al. Revival of the radial artery for coronary bypass grafting. Ann Thorac Surg 1992;54:652-60.

6. He G-W, Yang C-Q. Comparison among arterial grafts and coronary artery: an attempt at functional classification. J Thorac Cardiovasc Surg 1995;109:707-15.

7. Chardigny C, Jebara VA, Acar C, Descombes JJ, Verbeuren TJ, Carpentier AC, et al. Vasoreactivity of the radial artery: comparison with the internal mammary artery and gastroepipoic arteries with implications for coronary artery surgery. Circulation 1993;88[part II]:115-27.

8. He G-W, Yang C-Q. Use of verapamil and nitroglycerin solution in preparation of radial artery for coronary grafting. Ann Thorac Surg 1996;61:610-4.

9. Reyes AT, Frame R, Brodman RF. Technique for harvesting the radial artery as a coronary artery bypass graft. Ann Thorac Surg 1995;59:118-26.

10. da Costa FD, da Costa IA, Poffo R, Abuchaim D, Gaspar R, Garcia L, et al. Myocardial revascularization with the radial artery: a clinical and angiographic study. Ann Thorac Surg 1996;62:475-9.

11. He G-W, Yang C-Q. Radial artery has higher receptor-mediated contractility but similar endothelial function compared with mammary artery. Ann Thorac Surg 1997;63:1346-52.

12. He G-W, Yang C-Q, Starr A. Overview of the nature of vasoconstriction in arterial grafts for coronary operations. Ann Thorac Surg 1995;59:676-83.

13. He G-W, Buxton B, Rosenfeldt F, Angus JA. Reactivity of human isolated internal mammary artery to constrictor and dilator agents: implications for treatment of internal mammary artery spasm. Circulation 1989;80(Suppl):I-141-50.

14. He G-W, Shaw J, Hughes C, Yang C-Q, Thomson D, McCaughan B, et al. Predominant function of $\alpha_{1}$-adrenoceptors in the human internal mammary artery. J Cardiovasc Pharmacol 1993;21:256-63.

15. He G-W, Buxton B, Rosenfeldt F, Wilson AC, Angus JA. Weak $\beta$-adrenoceptor-mediated relaxation in the human internal mammary artery. J Thorac Cardiovasc Surg 1989;97:259-66.

16. He G-W, Yang C-Q, Graier WF, Yang J-A. Hyerkalemia alters EDHF-mediated hyperpolarization and relaxation in porcine coronary arteries. Am J Physiol 1996;271 (Heart Circ Physiol 40):H760-7.

17. Robertson RM, Wood AJJ, Vaughn WK, Robertson D. Exacerbation of vasotonic angina pectoris by propranolol. Circulation 1982;65:281-5.

18. Timmermans PBMWM. $\alpha$-Aadrenoceptors. In: Williams M, Glennon RA, Timmermans PBMWM, editors. Receptor pharmacology and function. 1st ed. New York: Marcel Dekker; 1989. p. 173-205.

19. Ohyanagi M, Faber JE, Nishigaki K. Differential activation of alpha 1- and alpha 2-adrenoceptors on microvascular smooth muscle during sympathetic nerve stimulation. Circ Res 1991:68: 232-44.

20. Parkinson NA, Thorn SM, Hughes AD, Sever PS, Mulvany MJ, Nielsen $\mathrm{H}$. Neurally evoked responses of human isolated resistance arteries are mediated by both alpha 1- and alpha 2-adrenoceptors. Br J Pharmacol 1992;106:568-73.

21. Langer SZ, Hicks PE. Alpha-adrenoceptor subtypes in blood vessels: physiology and pharmacology. J Cardiovasc Pharmacol 1984;6:s547-53.

22. Langer SZ, Sherpperson NB, Massingham R. Preferential noradrenergic innervation of $\alpha_{1}$-adrenergic receptors in vascular smooth muscle. Hypertension 1981;3(Suppl)112-8.

23. Ariens EJ, Simonis AM. Physiological and pharmacological aspects of adrenergic receptor classification. Biochem Pharmacol 1983;32:1539-45.

24. Molderings GJ, Gothert M. Subtype determination of presynaptic alpha 2-autoreceptors in the rabbit pulmonary artery and human saphenous vein. Naunyn Schmiedebergs Arch Pharmacol 1995;352:483-90

25. Bucher B, Corriu C, Stoclet JC. Prejunctional opioid mureceptors and adenosine A1-receptors on the sympathetic nerve endings of the rat tail artery interact with the alpha 2-adrenoceptors. Naunyn Schmiedebergs Arch Pharmacol 1992;345:37-43.

26. Medgett IC, Langer SZ. Heterogeneity of smooth muscle alpha-adrenoceptors in rat tail artery in vitro. J Pharmacol Exp Ther 1984;229:823-30.

27. Cambridge D. UK14304, a potent and selective $\alpha_{2}$-agonist for the characterization of $\alpha_{2}$-adrenoceptor subtypes. Eur J Pharmacol 1981;72:413-5. 